\title{
Central Bank Talk: Does It Matter and Why?*
}

\author{
Donald L. Kohn \\ and \\ Brian P. Sack \\ Board of Governors of the Federal Reserve System \\ Washington, DC 20551
}

\begin{abstract}
Statements released by the Federal Open Market Committee (FOMC) and congressional testimony by Chairman Greenspan are found to significantly affect market interest rates, indicating that central bank "talk" conveys important information to market participants. These effects arise not only because the statements provide information about the near-term policy inclinations of the FOMC but also because the statements convey information about the outlook for the economy. By contrast, statements raising questions about asset valuations typically have not generated a significant response of those asset prices.
\end{abstract}

August 25, 2003

\footnotetext{
* The opinions expressed in this paper are those of the authors and do not necessarily reflect the views of other members of the Federal Reserve Board or its staff. This paper was prepared for a Festschrift for Chuck Freedman hosted by the Bank of Canada on June 20, 2003, and it will appear in a forthcoming volume of those proceedings. We thank Paul Jenkins, Vincent Reinhart, Athanasios Orphanides, and participants of a Federal Reserve Board research group for comments. Jeffrey Slone provided exceptional research assistance.
} 


\section{Introduction}

Central banks around the world have become considerably more transparent over the past decade. A key element of this increased transparency has been more extensive efforts by central banks to communicate their views about the economic outlook, the important elements shaping that outlook, and the possible consequences for monetary policy.

This paper investigates the effects of central bank statements and draws some inferences about their use by central banks. The paper was prepared for a Festschrift hosted by the Bank of Canada in honor of Chuck Freeman, who has played a leading role in highlighting the potential benefits of central bank communication and realizing them in practice (see, for example, Freedman $(1996,2002))$. He has stressed the value of transparency for improving the public's understanding and support of monetary policy and the democratic accountability of the central bank. In addition, he has emphasized that transparency can enhance the effectiveness of policy by fostering behavior in wages and prices and in financial markets that should help the central bank achieve its objectives of stabilizing prices and damping fluctuations in economic activity. Chuck has not just theorized about transparency - he has actively promoted it in his work at the Bank of Canada and in his collaboration with central bankers around the world. In his writings and conversations, Chuck stimulates the debate by probing and questioning practices in Canada and in other countries - what works and what doesn't, what helps clarify and what might confuse, and in what ways transparency helps economies perform better. It was in this spirit that we undertook the research for this paper.

Of course, the potential benefits of central bank "talk" will only be realized if private agents pay attention to what the central bank has to say. It is not obvious, a priori, in what ways statements by the central bank have a role in shaping the expectations of investors and other private agents. Investors presumably read statements for information about the near-term policy inclinations of the central bank - an area in which the central bank will know more than the private sector and can have new information to impart. Statements might also convey shifts in the central bank's views of the economic outlook and the associated risks, which in turn might influence investors' own expectations for the economy. But it is not entirely clear how large this effect may be, considering that 
the economic information available to the central bank is typically available to the public as well. Overall, the extent to which central bank statements provide information to private agents is a question that must be answered empirically.

The paper addresses this topic by looking for effects from three types of communication by the Federal Reserve since the beginning of 1989 - statements released by the Federal Open Market Committee (FOMC), congressional testimony by Chairman Greenspan, and speeches given by Chairman Greenspan. We first investigate whether these forms of central bank talk have had identifiable effects on various financial variables, independent of the effects of policy actions that coincided with them. The results indicate that FOMC statements and congressional testimony by Chairman Greenspan have had a considerable influence on short- and intermediate-term interest rates.

We then turn to determining the underlying reasons for these effects. The most obvious explanation is that the statements may be seen as partly revealing the near-term policy inclinations of the FOMC. We attempt to determine whether, in addition, some of the effects arise because the statements convey information about the economic outlook. Lastly, we consider whether a smaller set of statements in which Chairman Greenspan raised questions about the valuations of particular assets caused those asset prices to adjust.

This work is a first step in a research program to provide central banks with useful evidence on what kinds of communication are most successful for realizing the potential benefits of transparency. Our findings raise a number of issues regarding the use of statements by central banks. Among those, we consider whether statements provide the central bank with an additional policy instrument that has a degree of independence from its actions. In addition, we discuss whether the effects of statements depend on the type of statement, including whether investors focus on simple balance-of-risk assessments to a greater extent than the more detailed language of other statements. Lastly, our results address the issue of whether central banks can "talk down" (or "talk up") particular asset prices that they feel may be incorrectly valued. 


\section{Three Types of Communication by the FOMC}

The Federal Reserve, like other central banks around the world, communicates with the public through a variety of channels. In this paper, we focus on three types of central bank talk that we believe to be influential: FOMC statements released immediately following policy meetings or intermeeting policy actions, congressional testimony by Chairman Greenspan, and major speeches by Chairman Greenspan. In this section, we describe each of these in more detail. For most of the analysis that follows, we consider Federal Reserve communication that took place between January 3, 1989, and April 7, 2003.

\section{FOMC Statements}

Policy statements that accompany FOMC actions or meetings are an important form of communication by the FOMC, given that they are released frequently and that they receive intense scrutiny by market participants. Of course, the timing and content of these statements have changed over time, as described in Table 1. From January 1989 to December 1993, the FOMC typically relied on open market operations, rather than statements, to signal shifts in the stance of monetary policy. On most occasions over this period, market participants were able to identify policy changes in a timely manner, but they were not provided with any rationale for those changes. The exceptions were changes in the federal funds rate that accompanied changes in the discount rate. In those instances, the Federal Reserve Board would produce a press release with a brief rationale for the discount rate change, which presumably also explained the change in the federal funds rate. ${ }^{1}$

From February 1994 to November 1998, the FOMC began releasing statements that accompanied changes in the federal funds rate. ${ }^{2}$ Those statements offered a brief description of the rationale for the policy action. The statements did not, however, include an explicit assessment of the risks going forward. Market participants could learn about the near-term policy inclination of the FOMC, or the so-called "policy tilt," by

\footnotetext{
${ }^{1}$ In this paper, we use the term FOMC statements loosely, since they include statements that were issued by the Federal Reserve Board with discount rate changes; our sample contains eight such statements. ${ }^{2}$ Those statements began to explicitly reference the federal funds rate only in July 1995. Even before then, though, the level of the funds rate target was well known.
} 
reading the minutes that were released after the subsequent FOMC meeting, but those minutes were typically viewed as being too stale to provide much significant information.

At its December 1998 meeting, the FOMC implemented an important change in its disclosure practices. In addition to releasing statements accompanying policy actions, the FOMC decided to release statements when "it wanted to communicate to the public a major shift in its views about the balance of risks or the likely direction of future policy." It first did so at the May 1999 FOMC meeting, when it announced a policy tilt toward tightening, and it subsequently released a statement indicating its policy tilt at every meeting over the remainder of the year.

FOMC disclosure policy changed again in January 2000, when the Committee announced that a statement would be released after every FOMC meeting and would always include an assessment of the "balance of risks." This balance-of-risks assessment involved new language that was linked more closely to the Committee's macroeconomic objectives than to the near-term direction of policy. More specifically, the statement would indicate whether the risks to the outlook for the economy over the "foreseeable future" were weighted toward "heightened inflation pressures" or "economic weakness" or whether those risks were balanced. This policy remained in effect until March 2003, when the Committee released a statement that refrained from assessing the balance of risks. At the subsequent meeting, in May 2003 (which falls after the end of our sample), the Committee again altered its risk assessment to allow the specification of two-sided risks to both inflation and economic growth.

Our sample includes 114 FOMC meetings and sixty-two changes in the federal funds rate - twenty-eight of which were intermeeting moves. Grouping FOMC meetings with intermeeting actions gives us 142 "FOMC decision" days. In total, statements were released on fifty-six of those FOMC decision days. The amount of information provided in these statements surely varied over the sample, but no trend was significant enough to take into consideration, and so we do not make distinctions across these days in the analysis below. ${ }^{3}$

\footnotetext{
${ }^{3}$ Our sample includes two statements (March 1994 and April 1994) that conveyed no information beyond the change in the federal funds rate. Our results are strengthened slightly if we exclude those statements.
} 


\section{Testimony by Chairman Greenspan}

The second form of communication that we consider is congressional testimony by Chairman Greenspan. The Chairman has testified on a variety of topics in front of many congressional committees. We will focus on a subset of his testimonies in which he focused on current economic conditions, the economic outlook, and monetary policy. The testimonies that seem to receive the most attention are those that accompany each semiannual Monetary Policy Report to the Congress. Those testimonies focus explicitly on the state of the economy and, along with the Chairman's answers to questions posed by the members of the committee before which he appears, receive considerable scrutiny by market participants. ${ }^{4}$ We also consider testimony by Chairman Greenspan before the Joint Economic Committee and the Senate or House budget committees. Those testimonies typically take place several times a year and receive considerable attention in the financial press, in part because they, too, often discuss current economic issues. Our sample includes sixty-six testimonies by Chairman Greenspan, of which twenty-nine accompanied the Monetary Policy Report.

\section{Speeches by Chairman Greenspan}

The third type of communication we consider is speeches by Chairman Greenspan. The Chairman speaks to a variety of audiences on a large number of topics. We consider all of his speeches from June 1996 to the end of our sample. ${ }^{5}$ Over that period, Chairman Greenspan gave 123 speeches, or an average of about eighteen per year. We found no apparent trend in the annual number of speeches that he has given. Of course, other members of the FOMC give speeches that also convey important information to market participants, but here we limit our focus to those by Chairman Greenspan.

\footnotetext{
${ }^{4}$ This testimony was previously known as the Humphrey-Hawkins testimony because it was required by the Full Employment and Balanced Growth Act of 1978 (sponsored by Senator Hubert Humphrey and Representative Augustus Hawkins). The reporting requirements of this Act were subsequently repealed, but the Federal Reserve continued to submit reports and give testimony on the same schedule. In 2000, the Congress reinstated a requirement to provide a report and testimony. The requirement includes two days of testimony. Since the second day often follows soon after the first and to a large extent contains the same material, we include only the first day of testimony in our sample.

${ }^{5}$ The dates of the Chairman's speeches were obtained from the Federal Reserve's public web site, www.federalreserve.gov. The list of dates is available from the authors.
} 


\section{Does Central Bank Talk Matter?}

Our first objective is to determine whether the three types of central bank communication described in the previous section have conveyed relevant information about the economy and asset prices to investors and other private agents. To address this question, we investigate whether Federal Reserve communication (a term we will use to encompass all three types of talk) has had a significant effect on financial market variables from January 3, 1989, to April 7, 2003. The financial variables we consider are the federal funds futures rate expiring three months ahead, eurodollar futures rates expiring two and four quarters ahead, two- and ten-year Treasury yields, one-year Treasury forward rates ending one to four years ahead, the S\&P 500 index, and the foreign exchange value of the dollar. ${ }^{6}$

The three types of communication considered provide us with a relatively large set of dates to investigate the effects of central bank talk. As described above, our sample includes fifty-six days on which the FOMC released a statement with its policy decision, sixty-six days of testimony by Chairman Greenspan, and 123 days (since 1996) on which the Chairman gave speeches. We begin by focusing on the effects of FOMC statements.

\section{Effects of FOMC Policy Statements}

The primary difficulty in assessing whether FOMC statements have an effect on financial variables is that no clear way exists to quantify those statements. Considering this difficulty, we focus on the volatility of the financial variables on days of FOMC statements. The basic idea is that if policy statements have an effect on the financial variables, then the volatility of those variables should be higher on the days of policy statements than it otherwise would be. ${ }^{7}$ By focusing on volatility, we can determine

\footnotetext{
${ }^{6}$ The federal funds and eurodollar futures rates are from the Chicago Board of Trade and the Chicago Mercantile Exchange respectively; the Treasury yields are par off-the-run yields from a yield curve estimated at the Federal Reserve Board; the Treasury forward rates are also derived from that yield curve; the $\mathrm{S} \& \mathrm{P}$ index is taken from Bloomberg; and the dollar is a trade-weighted index against major U.S. trading partners calculated by the Federal Reserve Board.

${ }^{7}$ This idea is also pursued by Bomfim and Reinhart (2000), who investigate whether the volatility of various financial variables on FOMC days has increased since 1994, when the FOMC began releasing statements. They do not find a significant change. However, unlike the analysis below, theirs does not focus specifically on FOMC days that contained statements, which may account for the differences in our findings.
} 
whether statements had a significant effect on the financial variables without having to assign a sign or magnitude to the statements.

A complication arises because FOMC statements have always accompanied a decision about the setting of the federal funds rate. To control for the effects of contemporaneous policy actions, we allow each financial variable to respond to the unexpected component of monetary policy decisions. The unexpected component of policy decisions, denoted $\Delta f f^{u}$, is determined from the change in the current month's federal funds futures contract, as described in more detail in Kuttner (2001):

$$
\Delta f f^{u}=D /(D-d) \cdot \Delta f f 1
$$

where $D$ is the total number of days in the month, $d$ is the day of the month of the FOMC decision, and $\Delta f f 1$ is the change in the futures rate on the day of the policy decision. This measure is computed for all days with FOMC meetings and intermeeting actions over our sample, and it is set to zero for all other days. ${ }^{8}$

Of course, the financial variables considered may also be significantly affected by a number of other factors, including macroeconomic data releases. Some of those data releases took place on the days of monetary policy surprises, thus affecting the volatility of the financial variables on those days. This consideration may be particularly relevant for the period before 1994, when a number of FOMC actions took place between meetings and, often, directly in response to data releases. We address this issue by allowing the financial variables to also respond to the surprise component of a number of data releases, where the surprise is computed as the realized value (as it was published that day) less the expected value from a survey conducted by Money Market Services. ${ }^{9}$ We denote the $i$ th macroeconomic data surprise $m a c_{i}^{u}$, which is set to zero for all days that did not involve that data release.

\footnotetext{
${ }^{8} \mathrm{We}$ exclude the policy easing on the morning of September 17, 2001, because of the disruption in financial markets around that period.

${ }^{9}$ The expected values are the median responses from the most recent Money Market Services survey, which is typically conducted the Friday before each data release. Some of the macroeconomic surprise variables begin later in the sample because of availability of the survey data. We set all the surprises to
} 
Following the common event-study approach, we allow the daily change in each financial variable, $\Delta y$, to respond linearly to the unexpected component of FOMC policy decisions and to the macroeconomic data surprises, as follows:

$$
\Delta y_{t}=\beta_{0}+\beta_{1} \cdot \Delta f f_{t}^{u}+\sum_{i=2}^{n} \beta_{i} \cdot \operatorname{mac}_{i}^{u}+\eta_{t}
$$

In determining the set of data releases, we include all of those that were found to have a significant effect on the three-month-ahead federal funds futures contract. This procedure yields a set of thirteen relevant macroeconomic surprises, which we maintain for all the financial variables. As an example of the results, Table 2 reports the regression coefficients for the three-month-ahead federal funds futures rate and the one- to two-yearahead Treasury forward rate. (In all the results that follow, interest rate changes are measured in basis points, and changes in equity prices and the exchange rate are measured in percentage points.)

The error term from equation (2), $\eta$, captures any other factors affecting the financial variable, including the effects of policy statements. As described above, we are concerned with whether the volatility of this error term increases on the days of FOMC statements, which would indicate that those statements contained information that had a significant effect on the financial variable. Because the specification controls for the direct effect of the policy surprise in equation (1), the results determine whether statements have any effect beyond the contemporaneous policy decisions. By construction, the effect of the statements is orthogonal to the unexpected policy change, and so any portion of the statement that is correlated with policy actions will instead be captured by the coefficient $\beta_{1} \cdot{ }^{10}$ Thus, the results may, if anything, understate the effects of statements.

zero for the three-month period beginning on September 11, 2001, when many of the data releases were distorted in the aftermath of the terrorist attacks.

${ }^{10}$ This observation applies to all existing event-study papers as well. However, Bomfim and Reinhart (2000) find that the response coefficient did not change under the FOMC's new disclosure policy that began in 1994, suggesting that the correlation is limited. 
The results are reported in Table 3. The first column shows the variances of the error term for each financial variable on all non-FOMC days in the sample - that is, days that did not involve policy actions, meetings, or any of the three types of Federal Reserve communication. These values represent the typical magnitude of the movements that arise from all the factors not included in our regressions, such as additional information about the macroeconomic outlook, shifts in investors' risk preferences, and changes in the value of liquidity. These factors would be expected to be present on the days of FOMC statements as well, but the impact of the statement should boost the volatility of the financial variable above the level that would otherwise have prevailed.

With that in mind, we estimate whether the volatility of the financial variables on days of FOMC statements increases significantly relative to the level observed over the week preceding each statement. ${ }^{11}$ As reported in the second column of the table, the variances of many of the financial variables - particularly shorter-term interest ratesincrease significantly and by a large amount on days of FOMC statements. ${ }^{12}$

Of course, it could be the case that the volatility of the error term for these variables tends to be elevated on all days of FOMC policy decisions, regardless of whether a statement is released or not. To allow for this possibility, we estimate the shift in volatility on FOMC decision days that did not involve the release of statements. As indicated in the third column, volatility does not shift on those days, implying that the systematic increase in volatility reported in the second column is associated with statements. $^{13}$

The most direct measure of the effect of statements is the difference between the shift in volatility observed on days of FOMC statements and that observed on FOMC days without statements. Under this measure, as reported in the last column, statements

\footnotetext{
${ }^{11} \mathrm{We}$ could have instead compared the volatility on all statement days to that on non-FOMC days. However, the above procedure better controls for patterns of volatility over the sample. For example, equity prices are systematically more volatile in the last several years of the sample, when more statements also happened to be released.

${ }^{12}$ We perform this test by regressing the squared residual on a constant, a dummy variable indicating the week before the policy statement, and a dummy variable indicating the policy statement day. We obtain similar conclusions using a GARCH-based framework that follows the work of Andersen and Bollerslev (1997). Those results are available from the authors upon request.

${ }^{13}$ The significant negative coefficient on the federal funds futures rate seems to be driven by events in 1989, when that contract likely was not very liquid. If we begin the estimation in 1990, the shift in the
} 
have a sizable and very significant effect on near-term interest rates, including federal funds and eurodollar futures rates, the two-year Treasury yield, and Treasury forward rates out to two years. One might expect the rates on those instruments in particular to be the most sensitive to policy statements, given that they are heavily influenced by the expected path of monetary policy. (In section 4, we investigate in detail the reasons for the significant effects.) By contrast, FOMC statements do not appear to have a significant effect on the other financial variables considered, including ten-year Treasury yields, Treasury forward rates beyond two years, equity prices, and the foreign exchange value of the dollar - assets for which the effects of near-term monetary policy expectations may be smaller relative to other influences.

To gauge the importance of these effects, we compare the increase in the variance of a given instrument attributed to the statement to that induced directly by the realized monetary policy decision. As reported in the first column of Table 4, unexpected policy actions have a significant effect on many of the financial variables considered. Federal funds and eurodollar futures rates move in the direction of the policy surprise, with the effect moderating as the contract horizon extends out to one year. Similarly, the two-year Treasury yield and forward rates out to two years respond significantly in the direction of the policy surprise, while the ten-year Treasury yield and forward rates at longer horizons respond less strongly. Lastly, equity prices fall in response to a tightening surprise, and the dollar appreciates. Collectively, these results are qualitatively consistent with those found in the event-study literature. ${ }^{14}$

These estimated responses, along with the variance of the policy surprises observed over our sample (164 basis points), are used to compute the variances of the financial variables attributed to their direct response to policy actions. For the threemonth-ahead federal funds futures rate, the direct response to the policy action accounts for most of the increase in the variance on FOMC days (see the last three columns of table 4). However, as the period covered by the instrument moves farther ahead, interest

variance on non-statement FOMC days becomes insignificant, while that on statement days remains positive and strongly significant.

${ }^{14}$ Among others, see Bomfim (2003), Kuttner (2001), Rigobon and Sack (2002), and Bernanke and Kuttner (2003). The response of longer-term interest rates estimated in the present paper is smaller than that reported in Kuttner (2001). The difference appears to arise because we extend the sample from his ending date, June 6, 2000, to the end of our sample, April 7, 2003. 
rates are driven to a greater extent by the policy statement. Indeed, at horizons beyond one year, the response of the Treasury forward rate is driven more by what the FOMC says than by what it does. In this regard, statements appear to be an important component of the policy implemented by the FOMC.

One aspect of FOMC statements that receives considerable attention is the balance-of-risks statement. In light of that attention, we try to determine how much of the information from policy statements comes from the inclusion of the balance-of-risks assessment. To do so, we compare the shift in the variances induced by policy statements that include a balance-of-risks assessment to that induced by statements without a risk assessment. All statements since 1999 (with the exception of March 2003) have included some type of risk assessment, and so the difference is determined by comparing the effects of statements from the 1999-2003 period to those from the 1994-98 period. The results, which are not shown, indicate no significant difference in the shift in the variances of the financial variables. That is, statements that did not contain an assessment of the balance of risks seem to have had an effect on financial variables that was as large as ones that did contain such an assessment.

This result may be surprising to those who closely watch the market response to FOMC decisions, because market participants seem to focus quite intently on the balance-of-risks component of the statement. On some occasions, statements that did not contain an explicit risk assessment were read by market participants as containing this type of information. An example is the statement released with the FOMC policy action in August 1994. Although the FOMC tightened 14 basis points more than expected, the accompanying statement suggested that no additional policy actions would immediately follow. This seemingly "neutral" risk assessment sparked a rally in equity markets and a decline in Treasury yields. But even statements without such an obvious tilt appear to have generated a considerable response in financial markets.

\section{Effects of Testimonies and Speeches}

To measure the effects of the other forms of central bank talk consideredtestimonies and speeches by Chairman Greenspan-we rely on the same methodology. One difference from the above results is that these forms of communication are typically 
not accompanied by policy action, and so controlling for the unexpected component of current policy decisions becomes less important. Nevertheless, given that the model is estimated over all days in the sample, we continue to control for unexpected policy actions and economic data surprises. More specifically, we estimate equation (2) as above and investigate whether the variance of the error term increases on days of Chairman Greenspan's testimonies to Congress or on days of his speeches.

The results are presented in Table 5. As a reference for comparison, the first column repeats the results using FOMC statements (from Table 3). As was the case for FOMC statements, Chairman Greenspan's testimonies to the Congress have had a significant effect on many of the variables considered, including federal funds and eurodollar futures rates, the two-year Treasury yield, and Treasury forward rates. In fact, the estimated increases in the variances of those variables are larger and more significant for the Chairman's testimonies than they are for FOMC statements. Moreover, the effects of the Chairman's testimonies extend much farther out the yield curve, with a significant response found even for the ten-year Treasury yield.

The finding that the Chairman's testimonies have a significant effect on near-term interest rates is perhaps not surprising, because market participants would presumably focus on his comments for the same information contained in FOMC policy statements. However, the fact that significant effects are realized on much longer-term instruments provides a hint that the testimonies contain somewhat different information than that found in FOMC statements - a topic we consider in detail in the next section.

The results are much weaker for Chairman Greenspan's speeches. Indeed, we do not find significant effects on any of the financial variables in this case. The effects of some of his speeches, however, are likely diluted by the inclusion of other speeches that were not viewed as containing relevant information. Indeed, the Chairman gives speeches on a wide range of topics, and the extent to which those speeches touch on the current economic environment varies considerably. Judging from the effects of his testimonies, we believe that speeches that address the current or prospective economic environment are likely to generate a significant market response. Our approach probably includes enough instances in which he did not address those topics to obscure the effects of speeches that did. 


\section{Why Does Talk Matter?}

The previous section provided statistical evidence that statements by the FOMC and congressional testimony by Chairman Greenspan have had significant effects on a number of financial variables, particularly interest rates that span relatively short horizons. This section takes up the more difficult task of assessing why these forms of communication have elicited those responses. Most Federal Reserve communication probably contains some information about both the economic outlook and the expected near-term path of monetary policy. We attempt to distinguish the effects of these two components in the first subsection. A much smaller set of statements has addressed a different topic - the possibility that financial assets were improperly valued. We discuss those statements and their effects in the second subsection.

\section{Statements about Monetary Policy and the Economy}

The significant influence of FOMC statements and testimony by Chairman Greenspan on short-term interest rates presumably reflects their effects on investors' expectations for the near-term path of the federal funds rate. These revisions to expected policy could, to a large extent, be independent of any new information on the economy. Indeed, FOMC decisions involve considerable judgment and flexibility on the part of the Committee, and thus policy actions at any given time may be difficult to predict, even when investors have access to the same data as the Committee. With that in mind, investors clearly read statements for information about the near-term policy inclinations of the FOMC, even for a given state of the economy.

However, a portion of the revision to the expected path of monetary policy also likely reflects the fact that statements convey information about the FOMC's views of economic conditions. This information takes many forms. Some may pertain to aspects of the long-run behavior of the economy, including both those that are out of the influence of the FOMC (such as structural productivity growth) and those that are under its complete control (such as the desired inflation rate in the long run). The press coverage, however, leads us to believe that the preponderance of the information obtained from statements relates to the strength of aggregate demand and inflationary pressures 
over the next year or two. To simplify our analysis, we limit our focus to this type of information about the economy.

In the following exercise, we attempt to parse movements in interest rates with relatively short horizons into the two components just described —one capturing perceived changes in the near-term policy inclinations of the FOMC (independent of the near-term economic outlook) and one capturing perceived changes in the FOMC's view of the economic outlook (and the associated policy response). ${ }^{15}$ We will refer to these as the "policy-inclination" component and the "economic-outlook" component respectively.

To distinguish between these two components, we rely on the following observation: Even if the two components have the same effect on near-term policy expectations, they would presumably have very different effects on other asset prices. Consider, for example, a statement indicating that a policy easing is likely, which generates a response of near-term policy expectations of a particular magnitude (reflected in the three-month-ahead federal funds futures rate). If the shift in policy expectations were viewed as a response to unexpected economic weakness, it might lead to a sizable decline in intermediate-horizon forward rates, as investors would anticipate a drawn-out policy response to the weaker economic conditions. By contrast, if the shift in policy expectations were seen as reflecting only the near-term predilection of the FOMC, it would presumably have a much smaller effect on forward rates, as the movement in the federal funds rate would be expected to be transitory.

As the example suggests, the effects of FOMC statements can be separated into these two unobserved components by looking beyond their effect on short-term interest rates and considering the responses of other financial variables - notably forward rates at longer horizons. More specifically, in addition to the response of the three-month-ahead federal funds futures rate, we will consider the response of the Treasury forward rate covering the period from one to two years ahead. Of course, we could have chosen a number of other financial variables to use in the decomposition. However, this forward rate has the advantage of having a significant overall response to policy statements (Table 3 ), while still having very different responses to the two components considered.

\footnotetext{
${ }^{15}$ As discussed below, we focus on interest rates with relatively short horizons because the effects of FOMC statements seem to be limited to rates on instruments with maturities of two years or less (Table 3).
} 
On days of FOMC meetings and actions, we assume that the change in the two interest rates, denoted $\Delta f f 3$ and $\Delta f w d 1$, are determined by three unobservable factors, $\eta^{p o l}, \eta^{e c o n}$, and $\eta^{x}$, according to the following system of equations:

$$
\left[\begin{array}{c}
\Delta f f 3 \\
\Delta f w d 1
\end{array}\right]=\left[\begin{array}{ccc}
1 & 1 & 1 \\
\alpha & \beta & \gamma
\end{array}\right] \cdot\left[\begin{array}{c}
\eta^{p o l} \\
\eta^{e c o n} \\
\eta^{x}
\end{array}\right]
$$

The first two factors, $\eta^{p o l}$ and $\eta^{e c o n}$, are the policy-inclination and economic-outlook factors, respectively, which are present only on days of FOMC decisions or statements. The interest rates are also affected by other news, which we capture with an "other" factor, $\eta^{x}$, which is present on all days over the sample. ${ }^{16}$ The three shocks are assumed to be orthogonal to one another.

Our earlier results (Table 4) provide estimates of the increase in the variances of the two interest rates in response to FOMC actions and statements. We can also estimate the shift in the covariance between them using the same approach. Given the assumed structure in equation set (3), the shifts in the second moments of the two interest rates on FOMC days must be fully explained by the two policy-related factors, $\eta^{\text {pol }}$ and $\eta^{\text {econ }}$. The effects of these two factors on the near-term futures rate have been normalized to unity, and the effects on the Treasury forward rate are given by the parameters $\alpha$ and $\beta$. Thus, we have four variables (the two impact parameters and the variances of the two factors) to be estimated from three pieces of information (the shifts in the variances of the two interest rates and in their covariance). Without any additional information, the problem is not identified.

We can achieve identification if we can determine the relative responses of the two interest rates to either the policy-inclination component or the economic-outlook component - that is, either the $\alpha$ or $\beta$ parameter. Obtaining a measure of the former is difficult, as it would require finding unexpected policy actions that are clearly unrelated

\footnotetext{
${ }^{16}$ Realistically, the factor $\eta^{x}$ is multidimensional. This modification would not affect our results.
} 
to the state of the economy. However, an estimate of the latter can be derived on the basis of the response of asset prices to releases of macroeconomic data. These releases obviously do not contain any information about independent shifts in the FOMC's policy inclinations, but they clearly provide information about the economic outlookparticularly about the strength of aggregate demand or the extent of inflationary pressures that might be expected over the intermediate term.

Recall that in the results above, we estimated the response of the financial variables to a set of macroeconomic data releases. The results for the federal funds futures rate and the Treasury forward rate were shown in Table 2. The regression estimates can be used to determine the movements in those rates predicted by the actual data releases realized over our sample. This exercise indicates that macroeconomic shocks collectively have generated a response of the Treasury forward rate that is, on average, 1.70 times larger than the response of the near-term futures rate. This pattern likely reflects the fact that monetary policy displays some gradualism, which damps the expected response of policy in the immediate future. Moreover, this pattern is observed in response to many different types of data releases, including ones that are primarily indicative of the strength of aggregate demand and ones that are primarily indicative of inflation prospects. ${ }^{17}$

We use the relative response of the interest rates to macroeconomic news to pin down the parameter $\beta$, which is set to 1.70 . By calibrating $\beta$ this way, the factor $\eta^{\text {econ }}$ captures a component of policy-related effects that generates relative movements in the two interest rates identical to those found, on average, in response to macroeconomic data. We therefore interpret this factor as reflecting changes in investors' perceptions of the FOMC's outlook for the economy. That is, we assume that when investors revise their policy expectations in response to a perceived shift in the FOMC's economic outlook, they build in expectations of a gradual policy response identical to that observed when data releases cause a change in the economic outlook. ${ }^{18}$ Investors might also

\footnotetext{
${ }^{17} \mathrm{We}$ find that the response of the forward rate relative to the near-term futures rate is 1.69 for a set of data releases containing only indicators of the near-term strength of aggregate demand, and 1.88 for a set of data releases containing only direct indicators of inflation. In fact, for every single data release considered, the response of the forward rate is larger in magnitude than that of the near-term futures rate.

${ }^{18}$ The relative importance of changes in the outlook for the strength of aggregate demand and for inflationary pressures is determined by the typical magnitudes of the surprises in the macroeconomic data.
} 
update their own perceptions about the economic outlook in response to the FOMC statement, a topic that we will discuss in greater detail in section 5.

The factor $\eta^{p o l}$ then captures the other component of policy-related effects - the near-term policy inclination of the FOMC. The effect of the policy-inclination factor, $\alpha$, will be estimated from the observed behavior of the two market interest rates on days of policy actions or statements. With $\beta$ known, it can be shown that the parameter $\alpha$ equals $\alpha=\beta /(x-1)$, where

$$
x=\frac{d \operatorname{Var}(\Delta f w d 1)-\beta^{2} \cdot d \operatorname{Var}(\Delta f f 3)}{d \operatorname{Var}(\Delta f w d 1)-\beta \cdot d \operatorname{Cov}(\Delta f f 3, \Delta f w d 1)} .
$$

In equation (4), $d \operatorname{Var}(\Delta f f 3)$ and $d \operatorname{Var}(\Delta f w d 1)$ denote the increases in the variances of the two interest rates in response to policy actions or statements, and $d \operatorname{Cov}(\Delta f f 3, \Delta f w d 1)$ denotes the shift in the covariance between them.

We begin by applying this approach to the days of FOMC policy decisions. The increase in the variances of the interest rates on those days comes from two sources - the direct effect of policy actions and the effect of FOMC statements (Table 3). We apply the decomposition to the total policy-related effects, or the sum of these components. The estimate of parameter $\alpha$ is 0.34 , a value indicating that revisions to policy expectations associated with the near-term policy inclinations of the FOMC generate a smaller response of the year-ahead forward rate. This pattern is consistent with a perception among investors that such shifts in policy are transitory in nature, which perhaps is not surprising given that those inclinations are independent of macroeconomic developments. Note also that the pattern differs considerably from that associated with shifts in the economic outlook, which have a larger effect at longer horizons. ${ }^{19}$

\footnotetext{
${ }^{19}$ The basic characteristic of the decomposition - that there is one transitory component and one persistent component - depends on our estimate of $\beta$. To assess the precision of this estimate, we use the estimated equations from Table 2 and the historical (joint) distribution of the shocks from those equations to generate 10,000 samples of the futures rate and the forward rate. We then compute the distribution of the parameter $\beta$ by measuring the relative responses of the two rates to macroeconomic news under each of those iterations. The parameter estimate appears fairly precise- the 95 -percent confidence interval for $\beta$ ranges from 1.55 to 1.76 . Under this range of values, the parameter $\alpha$ varies from 0.29 to 0.35 .
} 
In order to determine the relative importance of the two unobserved components, we first solve for their variances from the above decomposition. Recall that the relative effects of the economic-outlook factor have been imposed on the exercise, while those of the policy-inclination factor have been estimated. Thus, we are effectively asking whether any element of the effect of FOMC statements appears identical to the effect of macroeconomic data releases. If FOMC statements do not contain such an element, the exercise would simply set the variance of the economic-outlook factor to zero.

Table 6 reports the variance decomposition of the two interest rates. ${ }^{20}$ We first focus on the policy-related effects on days of FOMC decisions (the first three columns). The table repeats the total effects of policy actions and statements on the variances of the two instruments (shown earlier in Table 4) and then breaks down those effects into the two components discussed above. The results indicate that policy actions are mostly associated with the near-term policy inclinations of the FOMC; those actions have most of their effects on near-term interest rates and smaller effects on longer-term rates-a pattern similar to that of the policy-inclination factor. By contrast, the effects of policy statements are importantly driven by the economic-outlook factor, which accounts for a sizable portion of the effect on the futures rate and nearly all of the effect on the forward rate. Looking at the effects of policy actions and statements together, we find that the effects on the near-term futures rate predominantly reflect the policy inclinations of the FOMC, which is not surprising. The total policy-related effects on the forward rate are instead primarily associated with the economic-outlook factor, reflecting the importance of policy statements in determining that rate.

Lastly, we apply the same decomposition to the effects of Chairman Greenspan's congressional testimony. In doing so, we maintain the value of the parameter $\alpha$ so that we can interpret the factors in the same manner. ${ }^{21}$ (We do not consider the Chairman's speeches, since those were not found to generate a significant increase in the variances of the interest rates.) The results show that the factor associated with the economic outlook

\footnotetext{
${ }^{20}$ For the near-term futures rate, the proportions are determined directly by the relative variances of the unobserved components, given that the loadings on each factor are normalized to 1 . For the year-ahead forward rate, the variance induced by each factor is given by its squared loading multiplied by the variance of the factor.

${ }^{21}$ If we re-estimate the parameter $\alpha$, we get a value close to zero. But because the exercise assigns very little explanatory power to the policy-inclination factor, this parameter may not be estimated very precisely.
} 
completely dominates - it accounts for more than the total increase in the variance of both the futures rate and the Treasury forward rate.

In our view, it is unlikely that these testimonies do not contain any perceived hints of the near-term policy inclinations of the FOMC. However, we do find it plausible that relative to FOMC statements, the Chairman's testimony tends to focus more extensively on the intermediate-term outlook for the economy than on the immediate policy inclination of the FOMC. After all, many of the testimonies, including the semiannual testimony that accompanies the Monetary Policy Report to the Congress, are explicitly intended to update the Congress on economic conditions.

The testimonies also touch more frequently on longer-term issues for the economy, such as structural changes to productivity growth and fiscal policy. ${ }^{22}$ In that case, the market response might involve a factor associated with even more persistent interest rate responses, which the decomposition would likely group into the economicoutlook component. Given this consideration, the precise results from the decomposition should be interpreted with caution. Nevertheless, one conclusion clearly emerges from the analysis: The Chairman's testimonies strongly affect market interest rates in a manner that looks quite different from the effects associated only with perceived changes in near-term policy expectations.

\section{Statements about Asset Valuations}

Less frequently, Chairman Greenspan has made statements that fall into a distinct category - those that raise questions about the valuation of particular financial assets. Reviewing speeches and testimonies of the Chairman since the mid-1990s, we found ten occasions when the Chairman either directly or indirectly warned that equity valuations were potentially too high, and six occasions when he warned that credit spreads were potentially too narrow or bank lending terms too generous. ${ }^{23}$ Our list is not necessarily comprehensive, although we consulted a fairly large number of documents in our search.

\footnotetext{
${ }^{22}$ Indeed, we found earlier (Table 5) that longer-term interest rates show some reaction to the Chairman's testimony but none to FOMC statements.

${ }^{23}$ We also found one date, March 8, 1995, on which the Chairman commented on the value of the dollar. However, this is the only occurrence of such a statement over our sample, and we do not include it in the analysis.
} 
To assess the effects of such statements, we cannot employ the methodology used above. One problem is that the occurrence of comments on valuations is less frequent than statements about the economy or future policy. In addition, we are particularly concerned with the sign of the asset price response to these statements. Thus, we simply look at the behavior of those asset prices on the dates of the Chairman's comments and compare it in each case to the average volatility that occurred over the preceding month.

The results, shown in Table 7, indicate that these asset prices did not respond in a consistent way to the Chairman's comments. Of the ten comments on equity valuation, equity prices moved notably lower on only two occasions - in July 1998 and October 1999. In each of these instances, market participants clearly took note of the Chairman's comments on valuation, but the decline in equity prices probably cannot be entirely attributed to those comments. Indeed, in the first instance market participants were also disappointed that the Chairman did not hint at an imminent cut in the federal funds rate, while the second instance coincided with a surprisingly sharp jump in the producer price index. Moreover, the movements in equity prices on all the other days listed are within the range of two standard deviations of the changes observed over the month preceding each date (or are outside the range with the opposite sign). For example, the well-known "irrational exuberance" speech in December 1996 pushed down equity prices, but not by an unusually large amount. ${ }^{24}$

A similar story emerges for credit spreads. The table shows the response of the spread between the yield on high-yield bonds and the yield on a comparable Treasury security, although one should recognize that the Chairman's comments have covered a much wider range of credit instruments. The yield spread widened significantly on two of the six dates shown. However, market commentary on those days focused very little on the Chairman's comments about valuation. Moreover, on two of the other days listed, the yield spread instead narrowed significantly.

Overall, we conclude that market participants have not reacted strongly to the Chairman's comments about asset valuations. One possible explanation is that the statements have not been all that forceful and have in some cases been very indirect.

\footnotetext{
${ }^{24}$ Equity prices initially fell by about 2 percent that day, but by the end of the day they had recovered a considerable portion of that decline.
} 
However, we feel that the more likely explanation is that market participants simply choose not to strongly update their beliefs about the appropriate valuation of assets based on the Chairman's comments.

\section{Implications for Central Bankers}

Previous research has demonstrated that monetary policy actions affect the shape of the yield curve, and simple observation of financial market behavior indicates that central bank talk is also important in that regard. This paper has provided evidence on the extent to which central bank talk matters and on the channels through which it operates. In this section, we summarize our results and offer some thoughts on related issues. In doing so, we draw not only on the findings but also on our experience in the policymaking process at the Federal Reserve.

Our most important finding is that the forms of central bank communication considered appear to convey relevant information to investors and private agents. Indeed, the statements that accompany FOMC decisions have had significant effects on the shortand intermediate-term portion of the yield curve and on futures rates at those horizons. According to our estimates, interest rates with very short horizons respond more to what the central bank does (the unexpected portion of its policy decisions) than to what it says. However, at horizons one to two years ahead, FOMC statements account for at least as much of the movements in interest rates as the policy actions themselves. In addition, congressional testimony of Chairman Greenspan appears to have had even larger effects that extend to instruments with longer maturities.

Thus, understanding the effects of statements and determining the manner in which they could be used should be a topic of foremost interest to central banks. We have identified two different components of Federal Reserve communication that cause market interest rates to respond. First, investors presumably read statements for hints about the near-term policy tactics and intentions of the FOMC, without necessarily updating their view of the economy or their understanding of the central bank's view of the economy. We've labeled this component the "policy inclination" of the FOMC. Second, talk is also a way the Federal Reserve signals a revision to its assessment of the economic outlook. That revision affects rates further out the yield curve because the 
central bank is likely to act on its new outlook - and if it tends to react to such revisions gradually, the change in intermediate-term rates will tend to be greater than the change in short-term rates. We've labeled this second avenue the "economic-outlook" component. We argue that these components may be present in the effects of policy actions as well. That is, unexpected decisions by the FOMC may cause investors to reassess their views on the economy in addition to their perceptions of the near-term policy inclinations of the central bank.

Our decomposition suggests that the effects of FOMC statements arise to a large extent by conveying information about the economic outlook, while the effects of policy actions are transmitted primarily by altering perceptions of the FOMC's near-term inclinations. This pattern has implications for the determinants of interest rates with different horizons. Movements in very near term interest rates are largely in response to policy actions and thus are primarily determined by the policy-inclination factor. By contrast, movements in rates at the one- to two-year horizon, which are heavily influenced by policy statements, are driven to a large extent by changing perceptions of the FOMC's economic outlook.

The interpretation of the economic-outlook component raises an important issue - the extent to which investors update their own views on economic prospects in response to the information conveyed about the central bank's economic outlook. It is not entirely clear why a perceived shift in the FOMC's forecast, signaled through words or actions, would trigger a significant revision in the same direction to the economic forecasts of private agents. The Federal Reserve has little, if any, information that is not available to the market. ${ }^{25}$ However, private agents may still lend special credence to the economic pronouncements of the Federal Reserve and other central banks, particularly if the central bank has established credibility as an effective forecaster of the economy.

The Federal Reserve has been broadly correct on the direction of the economy and prices over the past two decades, on occasion spotting trends and developments before they were evident to market participants, and this record has enhanced its reputation and credibility. Indeed, Romer and Romer (2000) provide statistical evidence

\footnotetext{
${ }^{25}$ Although central banks can get information from the exercise of their bank supervisory or market stability functions, this information is critical primarily in crisis situations.
} 
that the Federal Reserve staff forecasts for output and inflation have been more accurate than private sector forecasts over the past several decades. As discussed in that paper, the impressive forecasting performance of the Federal Reserve may reflect the fact that it devotes considerable resources to analyzing and predicting the course of the U.S. economy - much more than any other entity. As a result, at least a part of the identified effects of the economic-outlook component likely reflects revisions to private forecasts of the economy.

Another reason to infer some updating of private forecasts is the magnitude of the change in the forward rate one to two years ahead. This rate presumably would not move as much if market participants thought the central bank was wrong in its assessment, because they would expect the Federal Reserve to at least partly learn about its error within a year or two. Instead, this component involves exactly the same term structure movement as found in response to macroeconomic data releases (which obviously contain actual economic news rather than perceived FOMC mistakes). Based on these arguments, it seems likely that investors at least partly update their own views on the economic outlook when the FOMC's outlook changes.

Of course, the effects of central bank statements are more complicated than assumed in this simple decomposition. We believe that the two factors identified are important components, but we also recognize that statements convey other relevant information at times. One possibility in countries without explicit inflation targets is that statements may provide information about the long-run inflation target of the central bank, information that could have an impact on interest rates with longer maturities. ${ }^{26}$ Our results did not indicate a systematic response of long-term interest rates to all FOMC statements taken together. However, the results do not rule out the possibility that market participants have on several occasions made this type of inference from FOMC statements. A second complication involves supply shocks, which have played a very important role in Federal Reserve policy and statements over the past decade. A credible central bank statement that the level or growth rate of potential output was higher than

\footnotetext{
${ }^{26}$ The statements could also contain information on the relative weights that the central bank places on its output and inflation objectives. In line with this idea, Ellingsen and Söderström (2003) attempt to decompose monetary policy surprises into those associated with responses to the economy and those associated with changes in central bank preferences.
} 
markets or the central bank had previously anticipated could have very different implications for the term structure than one that focused only on the prospects for the economy over the intermediate term.

The decomposition is forced to attribute all of the potential types of information to one of the two possible factors. As a result, our interpretations of those factors are somewhat imprecise and should be viewed as only suggestive. Nevertheless, the decomposition results clearly demonstrate an important characteristic of central bank statements - that they convey information beyond just the near-term policy inclinations of the FOMC.

The observation that statements have significant effects on market interest rates raises the question of whether releasing statements provides the central bank with an additional policy instrument. In some sense it does, but if so, it is an instrument whose use is very constrained. The central bank may have some discretion over whether to put out a statement or not, but it does not have complete discretion over its content - the statement is constrained to provide an honest assessment of the central bank's outlook for the economy.

In some circumstances, the temptation for the central bank to shade its assessments can arise from the very credibility of central bank forecasts. For example, a central bank that wants to indicate an imminent easing through a statement may be concerned that the statement will signal to investors that the economy is weak, thereby damping or even reversing any stimulative effect, say by depressing spending or reducing equity prices. We do not deny that such situations arise, but neither do we believe that they present overwhelming difficulties. After all, the statement provides only one piece of a broad array of information that investors and private agents use in formulating their views and in making economic decisions. To the extent it does have an effect, the statement should tend to move investors' forecasts closer to the appropriate level. Because this adjustment would have taken place eventually, the effect of the statement is simply one of timing.

Moreover, central bank statements can be very helpful in particular circumstances. They can be used to prevent investors from misinterpreting and overreacting to policy actions, and they can provide corrective information when the 
central bank believes that investors are unduly pessimistic or optimistic about the economic outlook. In regard to the first circumstance, statements can help market participants differentiate policy actions that respond to a major change in the economic outlook from those that are taken to provide insurance against a particular outcome in the context of a basically satisfactory outlook. Shaping accurate expectations about the economy and policy inclinations might be especially important when the nominal policy rate is very low and the central bank remains concerned about inadequate demand. In those circumstances, policy cannot as readily adjust through conventional actions to compensate for market perceptions that don't appropriately reflect the expectations and the intended strategy of the central bank.

Our results also suggest some interesting conclusions about the types of central bank statements that influence markets. One finding is that FOMC statements that contained a balance-of-risks assessment did not generate a larger market response than did statements without one. This result is somewhat surprising, given that market commentary seems to focus so much on the risk assessment. Although the risk assessment attracts a great deal of attention when it is included, it does not appear to be a necessary ingredient for conveying relevant information to market participants. That is, market participants do pay attention to the more extensive language that describes the economic outlook. This conclusion is supported by the sizable effect of Chairman Greenspan's congressional testimonies, which do not convey an explicit balance-of-risks assessment. Indeed, the effects of those testimonies are found to be larger and more significant (particularly at longer maturities) than the effects of FOMC statements, indicating that market participants find useful information in the more detailed discussions of the state of the economy and the outlook.

We would argue that providing more detailed language has considerable advantages over a simple, discrete categorization of the risks. A detailed statement, speech, or testimony can provide a more accurate description of the outlook for the economy, one that can better describe the various risks, describe how potential outcomes may be conditional on particular events, and provide the appropriate amount of nuance and caution regarding the central bank's views. Some of that information unavoidably gets lost when the central bank tries to describe those views with a simple summary, like 
a balance of risks assessment, a point forecast, or a brief statement. The summary can be given excessive weight by market participants who, in some circumstances, will not recognize the conditionality of the central bank's outlook and its unwillingness to commit itself to a particular course of action in an uncertain world. ${ }^{27} \mathrm{We}$ recognize, however, that it may be difficult to get a committee with diverse views to agree on a detailed statement. In that regard, a short statement that categorizes the outlook, such as the balance-of-risks assessment, may provide a useful communication device.

We find tentative evidence that one kind of central bank talk didn't matter at alldiscussions of asset price valuations. Indeed, a small set of Chairman Greenspan's speeches and testimonies that questioned the valuation of particular assets generally had no identifiable effect on the prices of those assets, suggesting that investors typically do not update their views about appropriate valuations in response to those comments. This finding is relevant to the argument, put forward by some, that the Federal Reserve could have damped the apparent stock market bubble of the late 1990s without actually adjusting monetary policy. According to these results, it would have been difficult, if not impossible, for the central bank to "talk down" the market, implying that the FOMC could have influenced stock prices only by using instruments that would have had broader consequences for the economy.

This last finding is also consistent with the overall conclusion of studies of foreign exchange market intervention and changes in margin requirements - two longstanding techniques that central banks have used to signal their assessment that asset prices had strayed from fundamentals. Those studies generally show that these efforts to influence asset prices are ineffectual unless they are expected to be backed up by changes in the stance of monetary policy. Apparently investors have not taken the Chairman's comments on equity valuations as a signal that policy will be adjusted directly in response. Indeed, asset prices per se are not in the legislative mandate of the Federal Reserve except to the extent that they affect macroeconomic stability, and hence the FOMC typically pays attention to asset prices only in the context of the economic outlook.

\footnotetext{
${ }^{27}$ The experiences of the Bank of Canada and the Reserve Bank of New Zealand with predicted paths for monetary conditions indexes that were read too literally by markets also illustrate the difficulties involved
} 
The impotence of the central bank to affect asset valuations contrasts sharply with the considerable effects of its statements on investors' expectations for monetary policy and their views about the economic outlook. Investors may simply perceive that the FOMC is much better informed about the near-term track for the economy and monetary policy than it is about the fair valuation of assets. After all, the FOMC has inside information about the potential course of monetary policy, and it might also be perceived as being an effective forecaster of near-term economic conditions. By contrast, many studies indicate that, in predicting asset prices, it is difficult to beat what is already priced into the market, and Chairman Greenspan himself has publicly questioned whether a central bank can determine the proper valuation of assets better than the market does. Consequently, it is not surprising that investors appear to have ignored warnings from the Federal Reserve about the level of equity prices.

\section{Avenues for Future Research}

Overall, investors seem to be quite attentive to central bank statements. Our results provide some tentative evidence on the nature of the effects of central bank talk. From a practitioner's standpoint, this is an important topic that warrants extensive research - the better we understand these effects, the better central banks will be able to structure their public pronouncements to achieve the benefits of transparency.

We believe that inflation-targeting countries provide fertile ground for estimating the differential effects of various kinds of talk. Inflation targeting is typically accompanied by an emphasis on the release of timely information about the views of the central bank, and that information often varies fairly widely in terms of detail and content. The Bank of England, for example, releases several relevant statements, including a statement from the Monetary Policy Committee, the minutes from its meetings within the intermeeting period, and an inflation report. An investigation of the extent to which these different statements affect financial markets, and whether they seem to convey different types of information, would be of particular interest.

In addition, we have not addressed a topic that is obviously critical to the potential benefits of central bank statements: whether central banks typically achieve the desired 
effect of their statements. Historical experience suggests that it is sometimes difficult to determine how market participants will interpret a given statement or whether they will put greater emphasis on particular passages than the central bank intended.

Another consideration is that there may be important interactions between central bank statements and policy actions. The analysis above focused on statement effects that were, by assumption, independent of policy actions. It could be the case, for example, that it is easier to reinforce the effects of a policy action with a statement in the same direction than it is to convey a message in the opposite direction. Such interactions are an interesting topic for further research.

\section{Conclusions}

Central banks will and should be judged on results - whether they achieve price stability and effectively stabilize economic activity around its potential. Monetary policy actions are without a doubt the essential ingredient for these results. But we also know that expectations - about both policy actions and economic conditions - play a central role in determining economic performance. Our results suggest that central bank statements, in addition to actions, importantly shape those expectations and thus should be viewed as a vital component of the monetary policy process.

We find that a portion of the effects of statements - what we call the policyinclination component - resembles the effects of realized policy actions with some difference in timing. That is, the policy-inclination component generates expectations of a transitory rate change that more or less match those observed in response to unexpected policy actions. Thus, statements and policy actions can serve as effective substitutes for one another, at least in the short run. Indeed, a credible central bank can probably achieve nearly the same result by implementing a policy action or by promising to implement that action at the next meeting. 
If this policy-inclination component were the only type of information, releasing statements would probably offer little improvement in social welfare, because the statements would have only minor effects on the timing of policy effects. However, our results suggest that statements also contain a component-what we call the economicoutlook component - that looks very different from policy actions. This component allows statements to serve an additional function - conveying changes in views about the economic outlook - that may be crucial to their welfare benefits. Indeed, it is probably this information that is the key to achieving much of the benefits of transparency, in that it allows private agents to better anticipate the course of policy and the economy and, as a consequence, to behave in a manner that reinforces the effectiveness of policy in achieving its objectives.

It stands to reason that efforts to improve transparency should be focused on this second component-elucidating the important elements in the outlook. This is not an easy task. The economy is complex and evolving in its structure, and it is constantly subject to unexpected developments. As a consequence, we argue that more detailed statements have advantages over simple summary statements, which are likely to be incomplete and potentially misleading. However, this argument may have practical limitations. One issue is that policy is made by a committee in most countries, a process that has the advantage of bringing a diversity of views to the policy process but that may pose challenges to agreement on a detailed statement. Despite this and other challenges, central banks must continue to extend and improve their use of statements, preferably with the assistance of additional research in this area. Advances along these lines should reinforce good monetary policy and enhance social welfare.

While we urge continued efforts to improve central bank statements about the economic outlook, we find that other types of talk - particularly statements about asset valuations - are less important. In general, central bank talk appears to be most influential (and hence potentially effective) when it focuses on issues about which the central bank is directly concerned and may have relevant information to convey. 


\section{References}

Andersen, T. and T. Bollerslev (1997), "Intraday Periodicity and Volatility Persistence in Financial Markets,” Journal of Empirical Finance 4, 115-158.

Bernanke, Ben S. and Kenneth N. Kuttner (2003), "What Explains the Stock Market's Reaction to Federal Reserve Policy?," Mimeo, Federal Reserve Board.

Bomfim, Antulio N. (2003), "Pre-Announcement Effects, News Effects, and Volatility: Monetary Policy and the Stock Market," Journal of Banking and Finance 27, 133-151.

Bomfim, Antulio N. and Vincent R. Reinhart (2000), "Making News: Financial Market Effects of Federal Reserve Disclosure Practices," Finance and Economics Discussion Series working paper no. 2000-14, Federal Reserve Board.

Ellingsen, Tore and Ulf Söderström, "Monetary Policy and the Bond Market," Mimeo, Stockholm School of Economics.

Freedman, Charles (1996), "What Operating Procedures Should Be Adopted to Maintain Price Stability? - Practical Issues," in Achieving Price Stability (Kansas City: Federal Reserve Bank of Kansas City), 241-285.

Freedman, Charles (2000), "The Value of Transparency in Conducting Monetary Policy," Federal Reserve Bank of Saint Louis Review 84, 155-160.

Kuttner, Kenneth N. (2001), "Monetary Policy Surprises and Interest Rates: Evidence from the Fed Funds Futures Market," Journal of Monetary Economics 47, 523-544.

Jones, Charles M., Owen Lamont, and Robin L. Lumsdaine (1998), "Macroeconomic News and Bond Market Volatility," Journal of Financial Economics 47, 315-337.

Rigobon, Roberto and Brian Sack (2002), "The Impact of Monetary Policy on Asset Prices," NBER Working Paper no. 8794.

Romer, Christina D. and David H. Romer (2002), "Federal Reserve Information and the Behavior of Interest Rates," American Economic Review 90, 429-457. 
Table 1

\section{History of FOMC Policy Statements}

\begin{tabular}{lll}
\hline Dates & Statements Released On: & Risk Assessment: \\
\hline $1 / 3 / 89^{1}$ to $12 / 21 / 93$ & Changes in the discount rate & None \\
$2 / 4 / 94$ to $11 / 17 / 98$ & Changes in the federal funds rate & None \\
$12 / 22 / 98^{2}$ to $12 / 21 / 99$ & $\begin{array}{l}\text { Changes in the federal funds rate } \\
\text { or "major shifts" in the outlook } \\
\text { All meetings (and intermeeting } \\
\text { changes in the federal funds rate) }\end{array}$ & $\begin{array}{l}\text { Included } \\
\text { (Balance of Risks) }\end{array}$ \\
\hline
\end{tabular}

${ }^{1}$ This date is the start of our sample.

${ }^{2}$ This change was decided at the $12 / 22 / 98$ meeting but was not disclosed until the minutes from that meeting were released on $2 / 4 / 99$.

${ }^{3}$ The exception in this period was $3 / 18 / 03$, when the FOMC released a statement that did not include a balance of risks assessment. 
Table 2

\section{Effects of Monetary Policy and Economic Data Surprises on Interest Rates}

\begin{tabular}{lcc}
\hline & $\begin{array}{c}\text { Federal Funds } \\
\text { Futures Rate } \\
\text { (Three months } \\
\text { ahead) }\end{array}$ & $\begin{array}{c}\text { Treasury } \\
\text { Forward Rate } \\
\text { (One to two } \\
\text { years ahead) }\end{array}$ \\
\hline Monetary Policy Surprises & $0.62(12.68)$ & $0.26(2.60)$ \\
Economic Data Surprises (normalized by their standard deviation): & \\
Capacity Utilization & & \\
Consumer Confidence & $1.0(4.73)$ & $2.6(4.90)$ \\
Core CPI & $1.3(3.59)$ & $3.0(5.23)$ \\
Durable Goods Orders & $1.2(3.88)$ & $2.4(3.70)$ \\
Employment Cost Index & $1.3(3.66)$ & $2.4(4.00)$ \\
Advance GDP & $2.4(5.11)$ & $4.8(4.13)$ \\
Initial Claims & $2.0(2.94)$ & $6.5(2.17)$ \\
ISM (NAPM) & $-0.3(2.01)$ & $-0.7(2.27)$ \\
Nonfarm Payrolls & $2.1(6.57)$ & $4.8(8.01)$ \\
New Homes & $3.9(8.58)$ & $5.8(7.02)$ \\
Core PPI & $0.9(4.12)$ & $1.5(2.91)$ \\
Retail Sales & $0.7(2.60)$ & $0.8(1.33)$ \\
Unemployment Rate & $1.4(3.98)$ & $1.8(2.47)$ \\
& $-1.6(3.60)$ & $-2.3(3.23)$ \\
& &
\end{tabular}

Table shows the results from a regression of the daily changes in each interest rate on the surprise components of monetary policy actions and economic data releases over the sample January 4, 1989, to April 7, 2003. Absolute t-statistics are shown in parentheses. Macroeconomic surprises are measured using the median expectation from a survey conducted by Money Market Services the Friday before each release. Monetary policy surprises are computed from federal funds futures rates. 
Table 3

\section{Effects of Policy Statements}

$$
\Delta y_{t}=\beta_{0}+\beta_{1} \cdot \Delta f f_{t}^{u}+\sum_{i=2}^{n} \beta_{i} \cdot m a c_{i}^{u}+\eta_{t}
$$

$\begin{array}{cccc}\operatorname{Var}(\eta) \text { on } & \text { Increase in } \operatorname{Var}(\eta) \text { on: } & \\ \text { Non-FOMC } & \text { FOMC with } & \text { FOMC w/o } & \text { Effect of } \\ \text { Days } & \text { Statements } & \text { Statements } & \text { Statements } \\ (1) & (2) & (3) & (2)-(3)\end{array}$

Federal Funds Futures:

3 months ahead $\quad 12.8 \quad 13.7^{* *} \quad-10.4^{* *} \quad 24.1^{* * *}$

Eurodollar Futures:

$\begin{array}{lrrrr}2 \text { quarters ahead } & 32.9 & 44.5^{* *} & -4.3 & 48.7^{* *} \\ 4 \text { quarters ahead } & 49.9 & 69.6^{* * *} & 5.2 & 64.5^{* *}\end{array}$

Treasury Yields:

$\begin{array}{lllrl}2 \text {-year } & 31.1 & 31.2^{* *} & -6.4 & 37.5^{* *} \\ 10 \text {-year } & 31.3 & 18.8 & 2.4 & 16.4\end{array}$

Treasury Forward Rates:

0 to 1 years ahead

1 to 2 years ahead

2 to 3 years ahead

3 to 4 years ahead

S\&P 500

Dollar
23.0

48.0

49.5

46.3

1.07

0.16
$23.7^{* *}$

$41.3^{*}$

$46.8^{*}$

38.3

$-0.04$

$-0.03$
$-5.3$

$-8.5$

3.1

9.7

$-0.05$

0.01

$-0.02$

**** indicates significance at the $1 \%$ level; ${ }^{* *}$ at the 5\% level; and ${ }^{*}$ at the $10 \%$ level. Non-FOMC days are all of those in the sample on which there was no FOMC meeting or policy action, no statement by the FOMC, and no testimony or speech by Chairman Greenspan. Increases in the variance of the error term are measured relative to that observed over the week preceding the FOMC decision. All interest rate changes are measured in basis points; changes in stock prices and the dollar are measured in percentage points. 
Table 4

Comparison of the Effects of Policy Actions and Statements

$\Delta y_{t}=\beta_{0}+\beta_{1} \cdot \Delta f f_{t}^{u}+\sum_{i=1}^{n} \beta_{i} \cdot m a c_{i}^{u}+\eta_{t}$

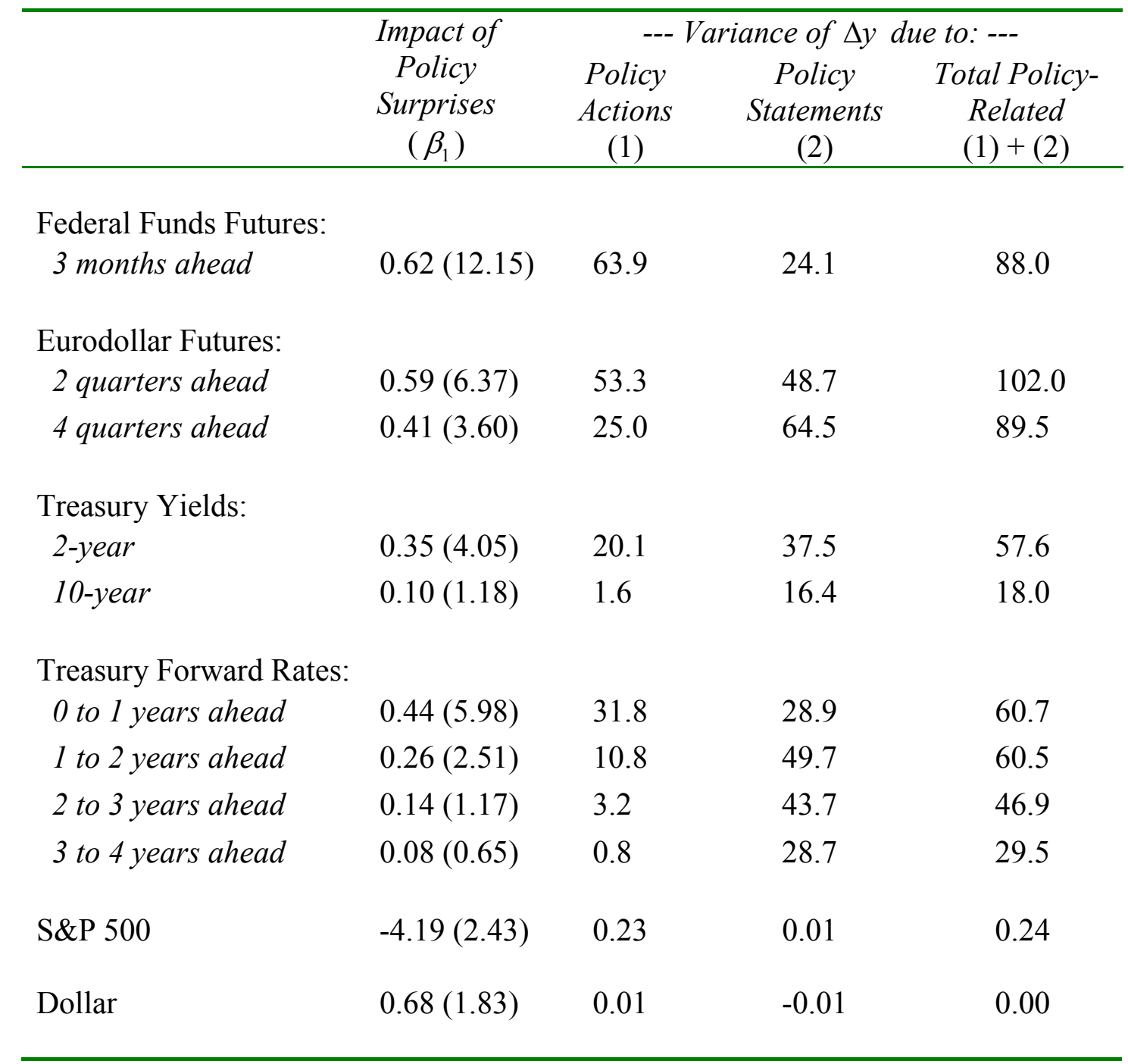

First column shows absolute t-statistics (corrected for heteroskedasticity) in parentheses. Those responses, along with the variance of the policy surprises observed over our sample (164 basis points), are used to calculate the variance of $\Delta y$ due to policy actions. All interest rate changes are measured in basis points; changes in stock prices and the dollar are measured in percentage points. 
Table 5

Comparison of the Effects of Different Types of Statements

$$
\Delta y_{t}=\beta_{0}+\beta_{1} \cdot \Delta f f_{t}^{u}+\sum_{i=2}^{n} \beta_{i} \cdot \operatorname{mac}_{i}^{u}+\eta_{t}
$$

\begin{tabular}{ccc}
\hline \multicolumn{3}{c}{ Increase in Var $(\eta)$ due to: } \\
FOMC & Greenspan & Greenspan \\
Statements & Testimony & Speeches \\
\hline
\end{tabular}

Federal Funds Futures:

3 months ahead $\quad 24.1^{* * *} \quad 10.0^{* *} \quad 1.0$

Eurodollar Futures:

2 quarters ahead

4 quarters ahead

$48.7^{* *}$

$45.6^{* *}$

7.4

$64.5^{* *}$

$101.7^{* * *}$

13.2

Treasury Yields:

$\begin{array}{llll}2 \text {-year } & 37.5^{* *} & 41.4^{* * *} & 4.3 \\ 10 \text {-year } & 16.4 & 37.1^{* * *} & 3.9\end{array}$

Treasury Forward Rates:

$\begin{array}{llll}0 \text { to } 1 \text { years ahead } & 28.9^{* *} & 21.8^{* *} & 2.1 \\ 1 \text { to } 2 \text { years ahead } & 49.7^{* *} & 69.3^{* * *} & 6.2 \\ 2 \text { to } 3 \text { years ahead } & 43.7 & 57.8^{* * *} & 4.1 \\ 3 \text { to } 4 \text { years ahead } & 28.7 & 45.2^{* * *} & 1.8 \\ \text { S\&P 500 } & 0.01 & -0.10 & -0.10 \\ \text { Dollar } & -0.01 & -0.05 & -0.01\end{array}$

${ }^{* * *}$ indicates significance at the $1 \%$ level; ${ }^{* *}$ at the $5 \%$ level; and ${ }^{*}$ at the $10 \%$ level. Increases in the variance of the error term are measured relative to that observed over the week preceding the FOMC statement, the testimony, or the speech. 
Table 6

Decomposition of the Effects of Policy Actions and Statements

\begin{tabular}{|c|c|c|c|c|}
\hline & \multicolumn{3}{|c|}{---- FOMC Decision Days ---- } & \multirow[b]{2}{*}{$\begin{array}{l}\text { Greenspan } \\
\text { Testimony }\end{array}$} \\
\hline & $\begin{array}{l}\text { Policy } \\
\text { Actions } \\
\text { (1) }\end{array}$ & $\begin{array}{c}\text { Policy } \\
\text { Statements } \\
\text { (2) }\end{array}$ & $\begin{array}{c}\text { Total Policy } \\
\text { Effects } \\
(1)+(2)\end{array}$ & \\
\hline \multicolumn{5}{|c|}{ Federal Funds Futures (3 months ahead): } \\
\hline $\begin{array}{l}\text { Total Effect on Variance } \\
\text { Of which: }\end{array}$ & 63.9 & 24.1 & 88.0 & 10.0 \\
\hline Policy Inclination & 62.7 & 7.2 & 69.8 & -14.6 \\
\hline Economic Outlook & 1.3 & 16.9 & 18.1 & 24.6 \\
\hline \multicolumn{5}{|c|}{ Treasury Forward Rates (1 to 2 years ahead): } \\
\hline $\begin{array}{l}\text { Total Effect on Variance } \\
\text { Of which: }\end{array}$ & 10.8 & 49.7 & 60.5 & 69.3 \\
\hline Policy Inclination & 7.2 & 0.8 & 8.0 & -1.7 \\
\hline Economic Outlook & 3.6 & 48.8 & 52.5 & 71.0 \\
\hline
\end{tabular}


Table 7

\section{Effects of Statements about Asset Valuations}

\begin{tabular}{|c|c|c|c|}
\hline Date & Event & $\begin{array}{c}\text { Change from } \\
\text { previous } \\
\text { business day }\end{array}$ & $\begin{array}{c}\text { Standard } \\
\text { deviation over } \\
\text { previous month }\end{array}$ \\
\hline
\end{tabular}

S\&P 500 (percent change):

12/06/96 Speech, American Enterprise Inst. $\quad-0.64 \quad 0.58$

02/26/97 $\quad$ Testimony on MPR to Congress $\quad-0.79 \quad 0.87$

07/22/97 Testimony on MPR to Congress $\quad 2.31 \quad 1.07$

02/24/98 Testimony on MPR to Congress $\quad-0.73 \quad 0.71$

07/21/98 Monetary Policy Report $\quad-1.61^{* *} \quad 0.65$

02/23/99 Testimony on MPR to Congress $\quad-0.08 \quad 1.44$

06/17/99 Testimony before the JEC $\quad 0.71 \quad 1.20$

07/22/99 Testimony on MPR to Congress $\quad-1.33 \quad 0.91$

10/15/99 Speech, conference sponsored by $\quad-2.81^{* *} \quad 1.22$

02/17/00 Testimony on MPR to Congress $\quad 0.04 \quad 1.32$

Credit Risk Spread (basis point change):

02/22/95 Testimony on MPR to Congress $\quad 7.1 \quad 7.4$

07/18/96 Monetary Policy Report $\quad 5.6 \quad 3.2$

02/26/97 Testimony on MPR to Congress $\quad-12.5 \quad 4.1$

07/22/97 Testimony on MPR to Congress $\quad 7.8^{* *} \quad 2.9$

02/24/98 Testimony on MPR to Congress $\quad-8.7 \quad 4.0$

06/17/99 Testimony before the JEC $11.7^{* *} \quad 4.9$

\footnotetext{
indicates that the decline in equity prices or the widening of credit spreads was greater in absolute value than two standard deviations of the movements observed in the preceding month. Speeches that were given after markets closed are dated as the following business day.
} 